\title{
Oxide Scales Revealed by Atom Probe Tomography.
}

\author{
Yan Dong $^{1}$, Talia Barth ${ }^{1}$, Yimeng Chen ${ }^{1,2}$, Emmanuelle A. Marquis ${ }^{1}$ \\ 1. Department of Materials Science and Engineering, University of Michigan, Ann Arbor, MI, U.S.A. \\ 2. CAMECA Instruments Inc., Madison, WI, U.S.A.
}

Atom probe tomography (APT) is now being used routinely to investigate phase transformations, clustering, and segregation phenomena not only metallic alloys but also ceramics and metal/oxide systems. Using designed experiments, APT in conjunction with transmission electron microscopy (TEM), electron back-scattered diffraction (EBSD), and focused ion beam (FIB) milling can provide a unique opportunity to gain insights into diffusion and transformation pathways during oxidation and corrosion of alloy systems. Selected analyses of oxide scales developing on various alloys during either high temperature oxidation or corrosion will be presented to discuss new opportunities in materials science and analytical challenges inherent to the APT technique.

Zirconium based alloys are widely used as cladding materials in nuclear power plants because of their low thermal neutron capture cross-section, adequate mechanical behavior and reasonable corrosion resistance. Yet waterside corrosion remains a major issue for utilizing these alloys when the fuel is operated at high temperatures and for extended residence times. Alloys with greater corrosion resistance are required to ensure the efficiency and reliability of nuclear power plants. APT analysis has been a key method to determine the distributions of alloying elements within alloys and oxide scales [1,2]. We will present and discuss the challenges associated with using APT for quantitative compositional analyses of oxide scale compositions forming on $\mathrm{Zr}$ alloys. Figure 1 illustrates the variations observed in the measured composition of the $\mathrm{ZrO}$ phase and how the results might depend on position within the APT specimen.

The beneficial effect of reactive elements (RE) on the oxidation behavior of Ni-based alloys has been widely observed with multiple reports highlighting reduced oxide growth rates and improved interfacial adherence of oxide scales, e.g. [3]. TEM evidence already exists for the segregation of REs to grain boundaries, e.g. [4]. The role of APT analysis and possible approaches to quantifying alumina grain boundary segregation on oxide scale formed on bare alloys or within more complex structure such as thermal barrier coatings will be discussed $[5,6]$.

\section{References:}

[1] Y Dong, A Motta, EA Marquis, J. Nuclear Materials 442 (2013) p.270.

[2] B de Gabory, Y Dong, A Motta, EA Marquis, J. Nuclear Materials 462 (2015) p.304.

[3] PY Hou, J Stringer, Materials Science and Engineering A, 202 (1995) p.1.

[4] B Pint, KL More, Journal of Materials Science, 44 (2009) p.1676.

[5] Y Chen, RC Reed, EA Marquis, Oxidation of Metals 82 (2014) p.457.

[6] Y Chen, RC Reed, EA Marquis, Scripta Materialia 67 (2012) p.779.

[7] This work was supported by the National science Foundation (grant \#DMR1352157), the US DOE Office of Nuclear Energy's Nuclear Energy University Program, and the University of Michigan College of Engineering. 

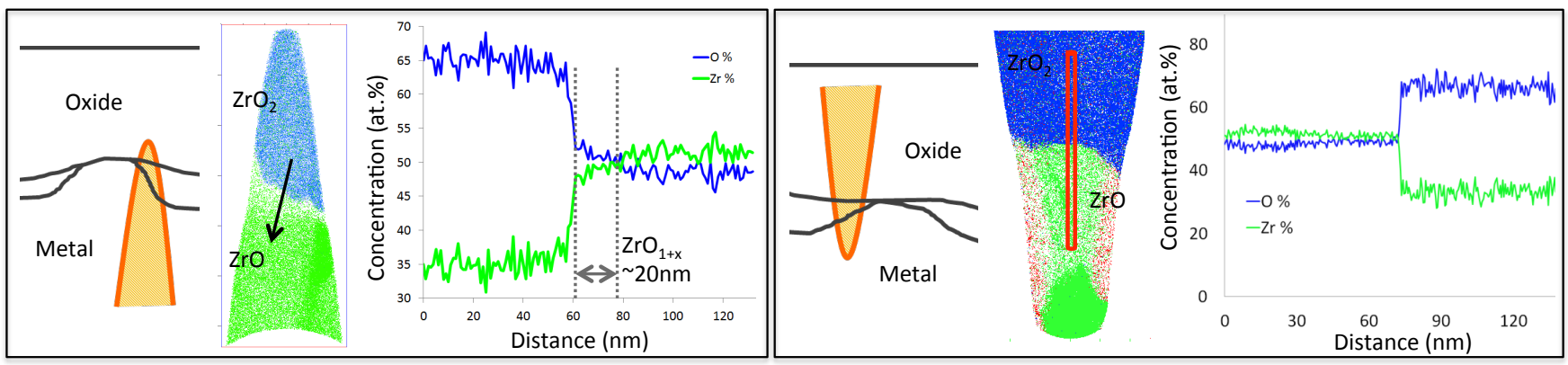

Figure 1: Variation of the measured $\mathrm{ZrO}$ composition with APT specimen orientation and location within APT specimen. The APT reconstructions show evaporated $\mathrm{Zr}^{3+, 2+}$ ions in green, evaporated $\mathrm{O}_{2}{ }^{+}$ ions in blue, and evaporated $\mathrm{ZrO}_{2}{ }^{2+},{ }^{++}$ions in red. These ions are representative of the $\mathrm{ZrO}$ phase with a slight measured $\mathrm{O}$ deficiency, $\mathrm{ZrO}_{2}$ phase, and the $\mathrm{ZrO}$ phase with a measured $\mathrm{O}$ excess $\left(\mathrm{ZrO}_{1+\times}\right)$. (Left) A thin $\mathrm{ZrO}_{1+\mathrm{x}}$ layer is observed between $\mathrm{ZrO}_{2}$ and $\mathrm{ZrO}$ when the specimen is prepared with the $\mathrm{ZrO}_{2}$ layer on top. (Right) the $\mathrm{ZrO}_{2} / \mathrm{ZrO}$ interface is sharper for specimens prepared upside-down - no $\mathrm{ZrO}_{1+\mathrm{x}}$ interfacial layer. However lateral variations are observed with the presence of $\mathrm{ZrO}_{2}{ }^{2+, 1+}$ molecules on the periphery of the reconstruction.

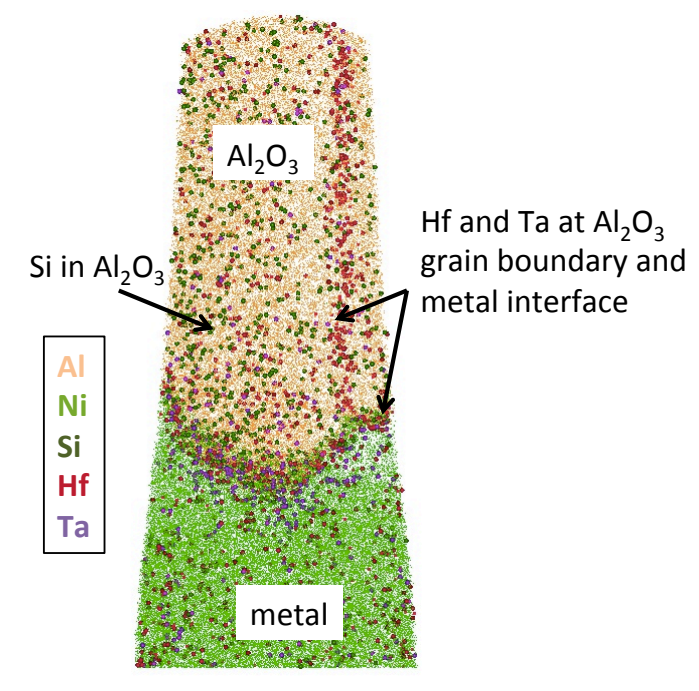

Figure 2: Reconstruction from the $\mathrm{Al}_{2} \mathrm{O}_{3} / \mathrm{Ni}$ alloy interface revealing $\mathrm{Hf}$ and Ta segregation at the metal oxide interface and oxide grain boundary. 